\title{
The Application of a Distributed Model of Active Media for the Analysis of Urban Ecosystems Development
}

\author{
Sidorova A.E.., Levashova N.T. ${ }^{\dagger}$, Semina A.E. ${ }^{\ddagger}$, Melnikova A.A. ${ }^{\S}$ \\ Faculty of Physics, M.V. Lomonosov Moscow State University, Moscow, Russia
}

\begin{abstract}
A model of spatiotemporal self-organization of urban ecosystems as a superposition of conjugate active media that takes into account inhomogeneities of anthropogenic and natural factors is proposed. The type of ecosystems under assumption is characterized by a high rate of population growth and density due to the concentration of residential, industrial, commercial and other objects, as well as communication media. These conditions reduce the "buffer capacity" of natural subsystems and increase the nonlinearity and consequently the instability of system processes within the boundaries of urban ecosystems. The model is based on the system of FitzHugh-Nagumo equations, modified by the authors so to take into account inhomogeneities of anthropogenic (activator) and natural (inhibitor) factors. The validity of the application of an equation of this type is determined by the relative simplicity of the system analysis of two equations of the "activatorinhibitor" type. The previously published analytical studies of a system of equations of this type made it possible to create on its basis an adequate model for urban ecosystems development. The numerical solution of the system in the twodimensional case was carried out in a rectangular region. On the boundaries of the domain the homogeneous Neumann conditions were given, the initial distribution was assumed to be known. The solution was carried out by the method of evolutionary factorization. The iterative process continued until complete stationing. The developed model is used for analysis and forecasting the development of the territory of New Moscow. The arrays of values of the control parameters of the model, which were subsequently taken into account in numerical implementation, were obtained on the basis of the aerial survey data and maps of the studied territories translated into digital form using the $\mathrm{C}++$ authoring application, which allows to create text files with image-based data. The code was created in the OpenCL environment and implemented using AMD FIREPRO graphics processors. Graphical interpretation was carried out using the "Serfer" program.
\end{abstract}

Key words: active media, autowave self-organization, urban ecosystem.

\section{INTRODUCTION}

Studying the laws of urban ecosystems (UES) development allows not only to create new ways of organizing urban space, ensuring effective interaction and balanced development of all spheres of life in UES, but also to predict the evolution of these territories. The first global simulation model for UES is the Forrester point model [1], which analyzes the dynamics of population density of urbanized areas relative to socio-ecological factors [2], but without

\footnotetext{
*sky314bone@mail.ru

†natasha@npanalytica.ru

‡syoanya@yandex.ru

\$melnikova@physics.msu.ru
} 
taking into account the spatial heterogeneity of urbanized areas. The authors of [3] used the Lotka-Volterra approach to model the topography of the landscape of urban ecosystems, including biocenoses. A significant drawback of this model is the additivity of the parameters considered, while the urban systems are non-homogeneous nonlinear systems, for which the principle of non-additivity is characteristic. Recently, the theory of cellular automata [4-7] was used for spatial-temporal modeling of urban ecosystems, with the help of the theory it was possible to simulate the process of territorial growth of some cities and propose their development forecasts. The authors of [7] represent the development of an urbanized territory not as a region with a square boundary made up of Moore cells, but approximate in shape to the circle, which more closely corresponds to the geometry of most cities in Europe and Asia. In [8], by estimating associated with the growth of urban areas changes in population size and density, statistical characteristics of the urbanized system are determined. In a number of works, the integration of cellular automata theory and neural networks is used for modeling cities' growth, for example the Indianapolis model [9], in which the influence of the system's "neurons" on processes is based on natural and socio-economic factors. Thus the simulation models of urban systems development are highly effective. However, it should be noted that there is a shortage of domestic model complexes, brought to computer implementation and tested on the data of real cities development.

\section{URBOECOSYSTEMS STRUCTURAL FORMATION MODEL AS A PROCESS OF AUTOWAVE SELF-ORGANIZATION IN ACTIVE MEDIA}

From our point of view, it is expedient to consider the process of UES structure formation from the standpoint of the theory of autowave self-organization in active media. The theory of reaction-diffusion systems (the simplest autowave equations) originates in the works of A.N. Kolmogorov, I.G. Petrovsky, NS Piskunov (KPP model, 1937), R. Fisher, Ya.B. Zeldovich and D.A. Frank-Kamenetsky $[10,11]$ and allows to solve the problems of an autowave passing through unexcited parts of the active medium. Models of active media are most widely used to describe biological systems, such as models for neuron processes [12], blood coagulation dynamics [13-15], and the shape of the impulses observed in the myocardium [16]. Among the simpler models of active media, the cubic and piecewise linear FitzHugh-Nagumo equations [17-20] were the most widely used for the biological systems description.

It is known that self-organization manifests throw the formation of autowave dissipative structures $[12,21]$. According to our theory, the city is proposed to be considered as a UES, composed by anthropogenic and natural conjugate subsystems. A necessary condition for selforganization in the UES is the synergetic correspondence of natural (biotic and abiotic) factors to the anthropogenic impact, that is determined by the structural and functional complexity of the ecosystem, the intensity of anthropogenic processes and the potential ability of natural subsystems to reduce these processes ("buffer capacity"). The driving parameters of this process are natural and anthropogenic factors (excitable elements) forming the autowave length and shape [22-27].

This type of ecosystem is characterized by a high rate of population growth and density due to the concentration of residential, industrial, commercial and other facilities, as well as communication media. These conditions violate the dynamic equilibrium of energy, substance and information flows, reduce the "buffer capacity" of natural subsystems, and increase the nonlinearity and consequently the instability of system processes. Being a conjugate active media, UES are the nonlinear dynamic macrostructures consisting of conjugated in time and space natural and anthropogenic subsystems. There is a distributed resource in the UES (population, industrial and residential objects, transport, geobiocenosis), and in the presence of perturbations in neighboring cells that lead to the changes in resource, the process is able to become autocatalytic. As a result of the increase in number and density of population, the 
residential, trade and industrial development, traffic flows the length of communications, grow and the borders of the UES expand. Due to this growing cities tend to merge into common systems, and hence the areas of geobiocenoses decrease and become fragmented; that inevitably leads to a change in the quantitative and, most importantly, qualitative composition of trophic networks [22-27]. At the same time, the rates of anthropogenic processes are at least an order of magnitude greater than the rates of natural processes [28], so we propose anthropogenic processes in the model as activators, and natural ones as inhibitors of system-wide processes.

To describe the dynamics of the UES development the authors of proposed a spatiotemporal system of equations based on the FitzHugh-Nagumo system [17-20].

$$
\begin{aligned}
& \frac{\partial u}{\partial t}-D_{u} \Delta u=-u(u-U \alpha(x, y))(u-U)-u v \\
& \frac{\partial v}{\partial t}-D_{v} \Delta v=-\gamma(x, y) v+\beta(x, y) u \quad x, y \in[-L ; L], t>0, \\
& \left.\frac{\partial u}{\partial x}\right|_{x=\mp L}=\left.\frac{\partial v}{\partial x}\right|_{x=\mp L}=\left.\frac{\partial u}{\partial y}\right|_{\mathrm{y}=\mp L}=\left.\frac{\partial v}{\partial y}\right|_{\mathrm{y}=\mp L}=0,
\end{aligned}
$$

where $u$ is the intensity of anthropogenic processes (activator); $U$ is the characteristic spatial variation of the activator; $v$ is the intensity of natural processes (inhibitor); $\alpha$ is the system activation parameter $(0<\alpha \leq 1)$; $\gamma$ is a kinetic parameter of inhibitor decay, $\gamma>0$; $\beta$ is a kinetic parameter of the activator-inhibitor interaction, $\beta>0 ; D_{u}, D_{v}$ are the diffusion coefficients of the activator and inhibitor, respectively; $L$ is the linear dimension of the considered region.

With regard to the problem of urban ecosystems development, the solutions of system (1) are of the special interest, having the form of propagating autowave fronts and stationary contrast structures, that is, functions undergoing sharp changes in narrow zones (transition layers) between the plots of urban development and natural biocenosis. The width of the transition layer is usually about several hundred meters, while the size of real urban ecosystems is tens of kilometers. Thus, the system (1) contains a small parameter equal to the ratio of the transition layer width to the value $L$, the linear dimension of the region under consideration. The introduction of a small parameter makes it possible to investigate system (1) by means of asymptotic methods.

We denote the small parameter as $\varepsilon$ and change the variables $(x, y)$ to $(x / \varepsilon, y / \varepsilon)$ in $(1)$. As a result the factor $\varepsilon^{2}$ arises before Laplacian in each of the equations in (1)

The role of an activator in urban ecosystems is given to the building or population growth rate. For actively developing metropolises, these values are large enough, and the parameter $U$ is comparable to $1 / \varepsilon$. It is convenient to normalize the values $u$ and $v$ by introducing new variables $u / U, v / U$. The relationship between the diffusion coefficients $D_{v} \sim \varepsilon D_{u}$ that is characteristic for the activator and the inhibitor is also to be taken into account.

As a result of the variable changes, system (1) acquires the form

$$
\varepsilon^{2} \frac{\partial u}{\partial t}-\varepsilon^{4} D_{u} \Delta u=-u(u-\alpha(x, y))(u-1)-\varepsilon u v, \quad \frac{\partial v}{\partial t}-\varepsilon^{2} D_{v} \Delta v=-\gamma(x, y) v+\beta(x, y) u .
$$

Here we retain notations for normalized functions and variables.

Putting $\varepsilon=0$ in the first equation (2) we obtain so-called "reduced equation" $f(u, x, y):=u(u-\alpha(x, y))(u-1)=0$. In case $0<\alpha<1$ this equation has three ordered roots: $u=0, u=\alpha(x, y), u=1$, moreover, the inequalities $f_{u}(0, x, y)>0, f_{u}(1, x, y)>0$ hold on. This is the condition under which system (2) models a bistable medium [12] in which autowaves of the moving front form occur [29]. 
As known [21], stationary contrast structures arise in media that are inhomogeneous in space coordinates. This model includes two factors that determine spatial heterogeneity: the population distribution as a function of coordinates and the presence of barriers that are urban geobiocenosis. The spatial inhomogeneity is expresses in the dependence of the quantities $\alpha$, $\beta, \gamma$ on the coordinates and this dependence is discontinuous in case of barrier presence. The conditions of stationary solutions existence for system (2) were obtained in [30], and the conditions under which stationary solutions with internal transition layers are formed at the barrier boundaries are contained in [31, 32].

\section{SPACE-TIME MODEL OF NEW MOSCOW DEVELOPMENT}

According to the development plans, the territory of New Moscow is divided into three zones (Figure 1, Table 1).

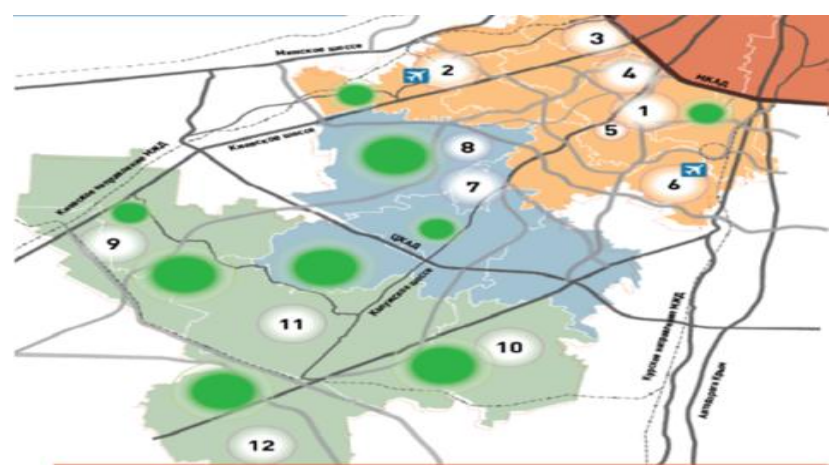

Fig. 1. New Moscow development plan (green spots mark geobiocenosis) [33].

Table 1. Density of building area in the territories of clusters [33]

\begin{tabular}{|c|l|c|}
\hline Zone & \multicolumn{1}{|c|}{ Type of building } & Density of building area, $\%$ \\
\hline 1 & Administrative and business, residential & 90 \\
\hline 2 & Historical-recreational and medical complexes & $80-70$ \\
\hline 3 & Agro-industrial complex & 50 \\
\hline
\end{tabular}

By 2035, a significant increase in the population (6.5 times) and in the real estate fund (4.2 times) is expected on New Moscow territory (Table 2).

Table 2. Dynamics of population and real estate fund in New Moscow territory [34]

\begin{tabular}{|c|c|c|}
\hline $\begin{array}{l}2012 \text { year } \\
\text { (the beginning of building) }\end{array}$ & 2015 year & $\begin{array}{c}2035 \text { year } \\
\text { (development planes) }\end{array}$ \\
\hline $\begin{array}{l}\text { Population is } 232 \text { thousand } \\
\text { people }\end{array}$ & $\begin{array}{c}\text { Population is } 310 \text { thousand } \\
\text { people }\end{array}$ & Population is expected to be 1.5 million people \\
\hline Housing stock is 24 million $\mathrm{m}^{2}$ & Housing stock is 31 million $\mathrm{m}^{2}$ & $\begin{array}{l}\text { Housing stock is expected to be } 60 \text { million } \mathrm{m}^{2} \\
\text { Uninhabited fund expected to be } 40 \text { million } \mathrm{m}^{2}\end{array}$ \\
\hline
\end{tabular}

Based on the map data and Moscow development, the authors constructed a mathematical model for the New Moscow development until 2030:

$$
\begin{aligned}
& \frac{\partial u}{\partial t}-D_{u}\left(\frac{\partial^{2} u}{\partial x^{2}}+\frac{\partial^{2} u}{\partial y^{2}}\right)=-\frac{1}{K^{2} T^{*}} u\left(u-N_{B} K \alpha(x, y)\right)\left(u-N_{B}\right)-\frac{1}{K T^{*}} u v \\
& \frac{\partial v}{\partial t}-D_{v}\left(\frac{\partial^{2} v}{\partial x^{2}}+\frac{\partial^{2} v}{\partial y^{2}}\right)=\frac{1}{T^{*}}(-v+\gamma \beta u) .
\end{aligned}
$$


Here $u$ is the built-up area; $v$ is the area of destroyed geobiocenosis. According to the adopted standards, the estimated area of biocenoses in New Moscow territory should be at least 25\% of the building area [33]. This is an inhibitor of building growth in the model. To coincide the dimensions, two coefficients are introduced: $T^{*}=1$ year is a time scale, $K=10^{-2} \mathrm{~km}^{2}$ is the characteristic area, that is area of average one-front door house with its green territory; $\gamma$ is the share of the destroyed geobiocenoses area from square kilometer; $N_{B}=80$ is the maximum number of buildings per square kilometer in accordance with the type of buildings (dense housing, cottage, industrial); $\beta=100 / N_{B}$ is the normalizing factor, that is the ratio of total square of area and the local building area; the function $\alpha(x, y)=e^{-0.05 K \rho(x, y)}$ characterizes the purpose of the land (availability and type of building); $\rho\left(\mathrm{km}^{2}\right)$ is the planned population density in these territories according to their purpose [33] (Table 3): for dense housing and industrial zone we accept $\rho=4000$ people $/ \mathrm{km}^{2}$, for cottage development $\rho=2000$ people $/ \mathrm{km}^{2}$, for parks (urbobiocenosis) $\rho=0$.

Table 3. Planned population density on territories according to their purpose [33]

\begin{tabular}{|c|c|c|}
\hline $\begin{array}{c}\text { Dense housing and industrial zone, } \\
\text { people/km }{ }^{2}\end{array}$ & $\begin{array}{c}\text { Cottage development, } \\
\text { people } / \mathrm{km}^{2}\end{array}$ & $\begin{array}{c}\text { Parks, } \\
\text { people } / \mathrm{km}^{2}\end{array}$ \\
\hline 4000 & 2000 & $\approx 0$ \\
\hline
\end{tabular}

$D_{u}$ Is the rate of building area growth $\left[\mathrm{km}^{2} / \mathrm{year}\right], D_{v}$ is the rate of decrease in the geobiocenosis areas.

After moving to dimensionless variables $u \leftrightarrow \frac{u}{K}, v \leftrightarrow \frac{v}{K}, D_{u, v} \leftrightarrow \frac{D_{u, v} T^{*}}{K}, \quad$ the system (3) turns into system (1).

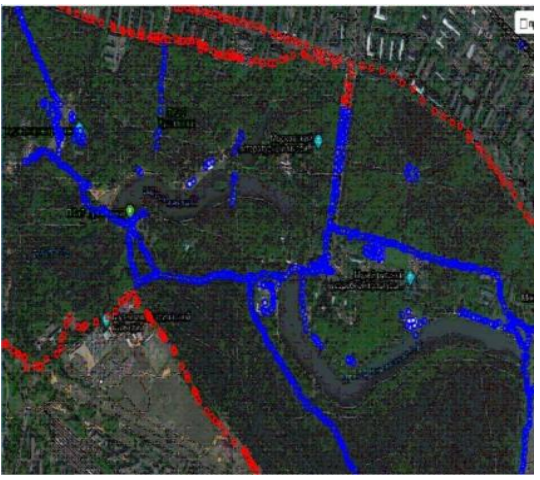

a) Kuzminki:

$89.42 \%$ - geobiocenoses $10.58 \%$ driveways

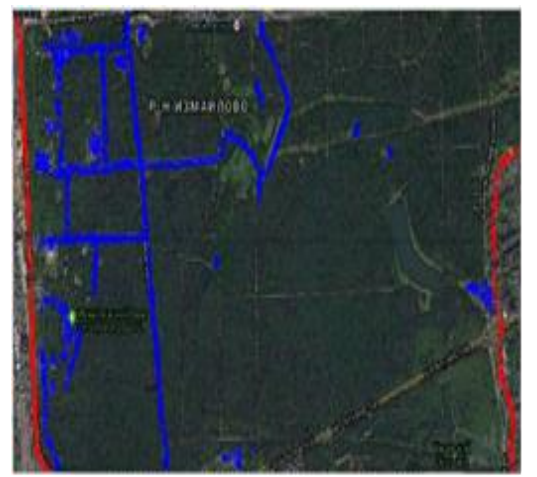

b) Izmailovsky Park:

$89.75 \%$ - geobiocenoses $10.25 \%$ driveways

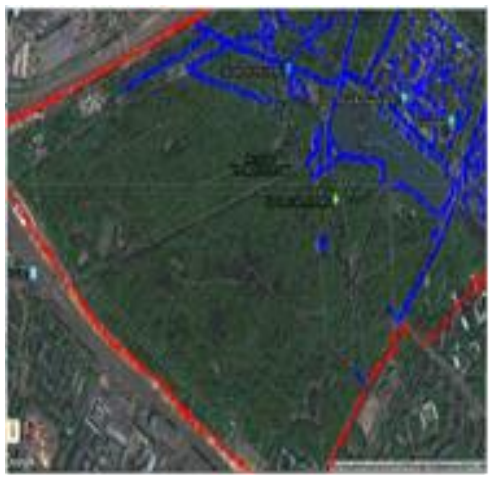

c) Park-estate Kuskovo:

$89.8 \%$ - geobiocenoses $10.2 \%$ driveways

Fig. 2. Processing of cartographic data on three characteristic park territories of Moscow [35] (authoring $\mathrm{C}++$ application, which forms text files from image-based data). On the map, asphalted or gravel roads are marked with blue dots; the borders of the park territory are marked in red in order to exclude the area of residential development from statistics.

To obtain the numerical value of the kinetic parameter $\gamma$, an analysis of characteristic park areas, industrial zones, dense housing and cottage development was made. The analysis was carried out using an authoring $\mathrm{C}++$ application, which forms text files from image-based data. The obtained data were used in the numerical implementation of the model. 
Based on the cartographic data of the three characteristic Moscow park territories, the calculation was carried out that revealed that the average area of geobiocenoses in these territories is about $10 \%$ (Figure 2).

For typical industrial development territories (Figure 3), the area of natural geobiocenoses is about $15 \%$.

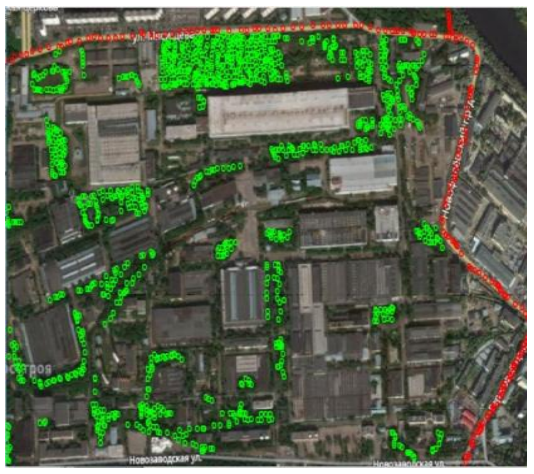

a) State Space Research and Production Center:

$83 \%$ - buildings and asphalted areas, $17 \%$ - geobiocenoses.

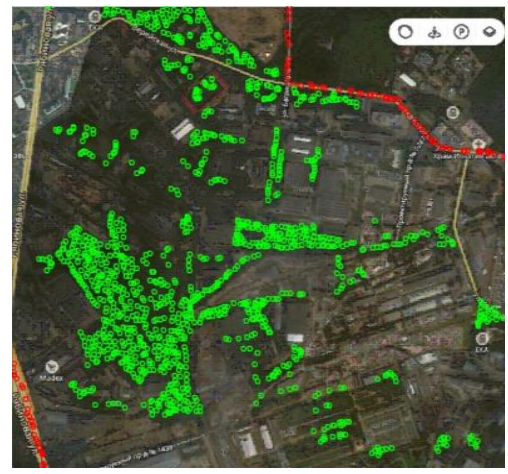

b) Radio Engineering Plant: $83 \%$ - buildings and asphalted areas, $17 \%$ - geobiocenoses

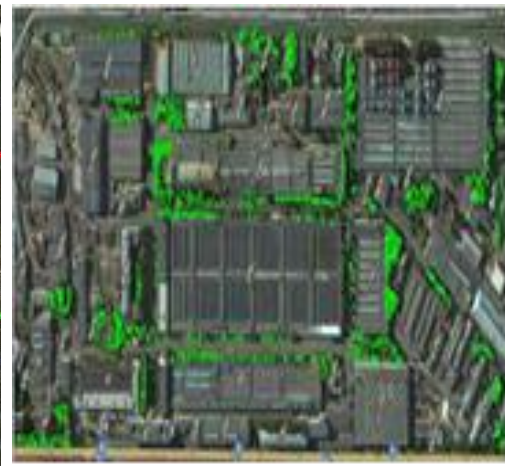

c) Research and Production Center of gas turbine construction: $88 \%$ - buildings and asphalted areas, $12 \%$ geobiocenoses

Fig. 3. Processing of cartographic data on three characteristic industrial areas of Moscow [35] (authoring $\mathrm{C}++$ application, which forms text files from image-based data). On the map, green points mark biocenoses; the borders of industrial territory are marked in red in order to exclude the area of residential development from statistics.

For typical areas of cottage development (Figure 4), the area of natural geobiocenosis is about $50 \%$.

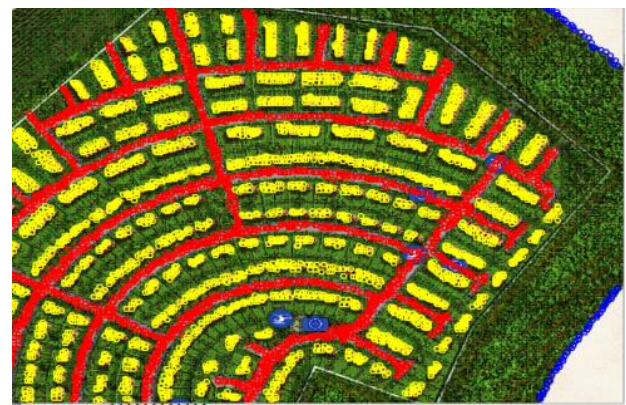

a) The cottage village Marseille (Kaluzhskoe highway, $30 \mathrm{~km}$ from Moscow Ring Road): $60 \%$ is geobiocenoses. [36]

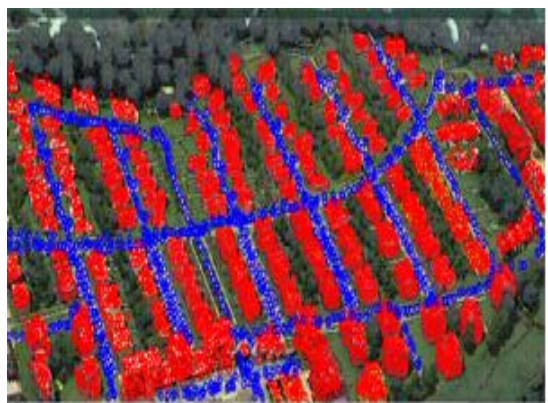

b) The Western Valley (Vnukovo): $47.5 \%$ is geobiocenoses. [37]

Fig. 4. Processing of cartographic data on cottage developments in New Moscow territory: (authoring $\mathrm{C}++$ application, which forms text files from image-based data). On the map, green markes geobiocenosis, red marks cottage development, and blue marks communications (roads, garages, etc.)

Analysis of statistical [33, 34] and cartographic [35] data from 2000 to 2017 for typical residential multi-storey complexes in the districts of Reutov, Khimki and Krasnogorsk was carried out to estimate the change in the area of residential development. It showed that during this period (on average) the change in the building area was $10 \%$, and the population change was $56 \%$ (Table 4). A slight increase in the development area is associated with the need to preserve the park zone of Moscow. However, this led to an increase in the height of buildings under construction and the density of buildings, which caused increasing of population in these areas. As a result, the area of social infrastructure (shopping areas, polyclinics, schools, kindergartens, roads, etc.) increased at the expense of natural 
geobiocenoses an average of $12 \%$, which led to the development in space of the autowave front of anthropogenic impact. As an example, the calculation of the development dynamics of Reutovo is given (Figure 5).

Table 4. The dynamics of the population and residential development of typical multi-storey complexes for the period 2000-2017 [38]

\begin{tabular}{|l|c|c|}
\hline \multicolumn{1}{|c|}{ District } & Population increase, $\%$ & Building area increase, $\%$ \\
\hline Khimki & 35.90 & 10 \\
\hline Krasnogorsk & 63.32 & 10 \\
\hline Reutov & 68.61 & 12 \\
\hline
\end{tabular}

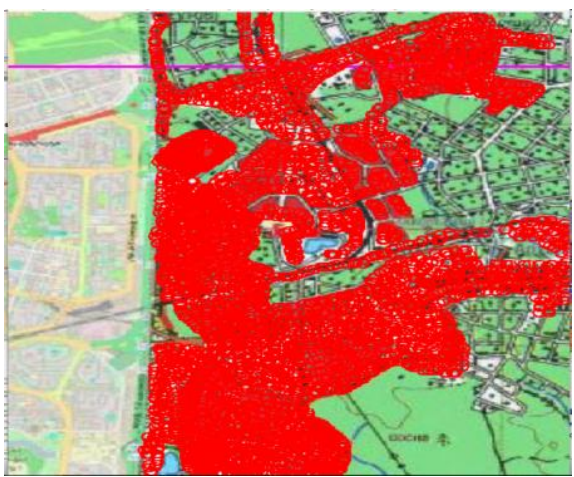

a) 2000

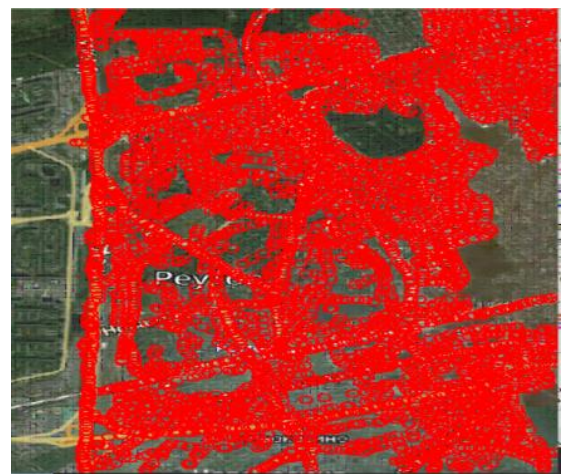

b) 2017

Fig. 5. Processing of cartographic data for Reutovo: a): $54 \%$ - geobiocenoses; b): $39 \%$ - geobiocenoses. On the map green marks geobiocenoses, red marks buildings (authoring $\mathrm{C}++$ application, which forms text files from image-based data).

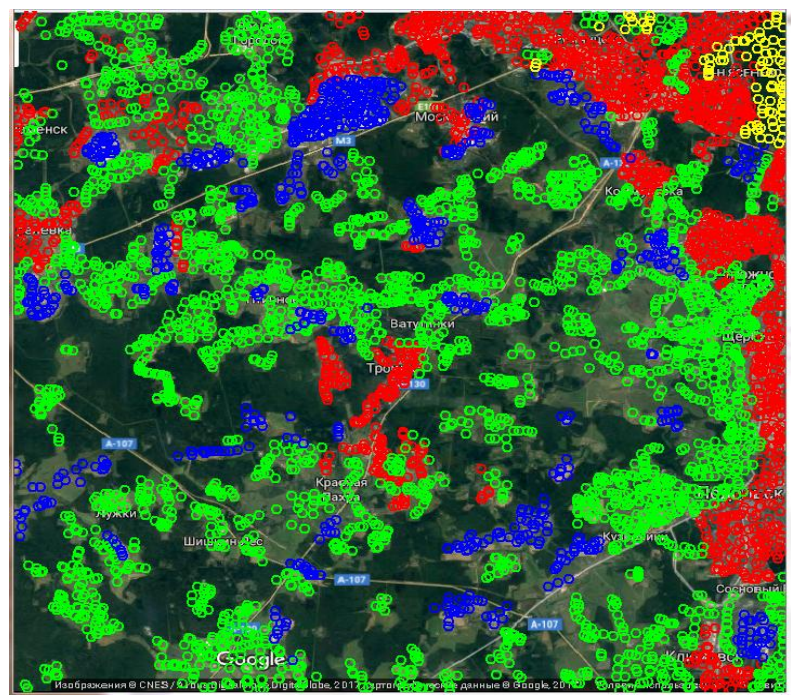

Fig. 6. Processing of map data on building in the territory of Novomoskovskiy Administrative District [35]. On the map, red marks the dense housing (population density 4000 people $/ \mathrm{km}^{2}$ ), bright green marks cottage developments (population density 2000 people $/ \mathrm{km}^{2}$ ), blue marks industrial complexes, yellow marks geobiocenoses on Moscow territory, dark green color marks the territory of forests and parks in the territory of NAO (authoring $\mathrm{C}++$ application, which forms text files from image-based data).

The obtained data made it possible to determine the numerical value of the kinetic parameter $\gamma$ in New Moscow development model: $\gamma=0$ for natural geobiocenoses; $\gamma=0.1$ for parks according to the calculations (Figure 2); $\gamma=0.5$ for cottage development according to $[33,34]$ and calculations (Figure 4); $\gamma=0.75$ for dense housing (according to the standards, 
the area of biocenoses should be at least $25 \%$ of the total area [33, 34]); $\gamma=0.85$ for industrial zones according to [33, 34] and calculations (Figure 3).

To test the model, the building site of the Novomoskovskiy Administrative District (NAD) in 2017 was considered. Based on aerial photography and maps [35] with use of the authoring $\mathrm{C}++$ application, which forms text files from image-based data, a $(70 \times 70)$-matrix of parameter $\alpha$ values was obtained, which was later used in numerical implementation according to the model. The results are shown in Figure 6.

\section{RESULTS OF NUMERICAL SIMULATION}

To carry out the calculations, according the model of New Moscow development until 2030 (Figure 7), the authors worked out a program code using the method of evolutionary factorization [39]. The code was created in the OpenCL environment and implemented using AMD FIREPRO graphics processors. Graphical interpretation was carried out using the "Serfer" program.

The assumptions of the model are as follow:

- Planned development areas and population density are taken according to [33, 34].

- The initial areas of geobiocenoses, including forests, parks and adjacent territories hold $55 \%$ of the total area of New Moscow (according to [33, 34]).

- The initial areas of natural geobiocenoses in built-up areas (house adjoining areas) hold $25 \%$ of building site [33].

- Taking into account the speed of New Moscow territory development and the rate of geobiocenoses destruction during the construction of residential and administrativeindustrial facilities, including the subsequent expansion of associated infrastructure territory (due to the population growth), we take $D_{v} / D_{u}=1 / 10\left(D_{u}=5 \mathrm{~km}^{2} /\right.$ year, $D_{v}=0.5 \mathrm{~km}^{2} /$ year $)$.

Analysis of the model data shows that there are two main ways for New Moscow development, the first of which is planned, the second is the predicted one:

1) The ratio of built-up areas and geobiocenoses is preserved (Figure 7,a), which corresponds to the standards $[33,34]$.

2) According to the existing practice of building, as the population grows, the areas of associated infrastructure (sidewalks, driveways, car parks, playgrounds, etc.) also expand, which leads to an increase in the anthropogenically transformed territories by 10-12\%.

According to the model (as a result of existing practice of development), the area of geobiocenoses are likely to decrease in future at expense of forests and parks territory. By 2024 geobiocenoses will decrease in area by $11 \%$ (of the total geobiocenosis area at the time of 2017) and by 2030 the decrease will be by $35 \%$ (Figure 7,b and 7,c). Thus, the total area of geobiocenoses in 2030 will be $39 \%$. As is known, the emergence of irreversible systemic processes occurs as a result of the destruction of more than $50 \%$ of systemic relationships. Such a scenario will lead to an additional reduction and fragmentation of natural geobiocenosis areas, the destruction of trophic networks and, consequently, to a decrease of natural autowave self-organization potential. 
SIDOROVA et al.
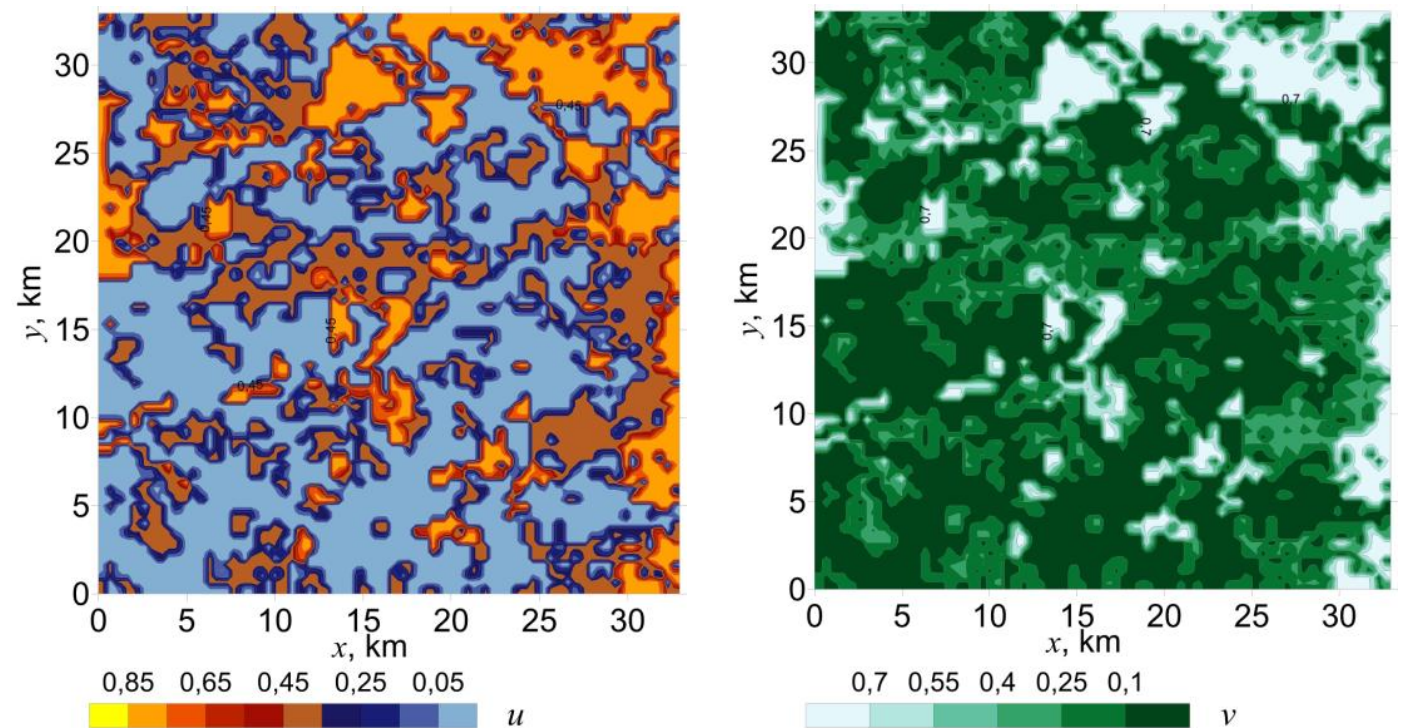

a) 2017 .
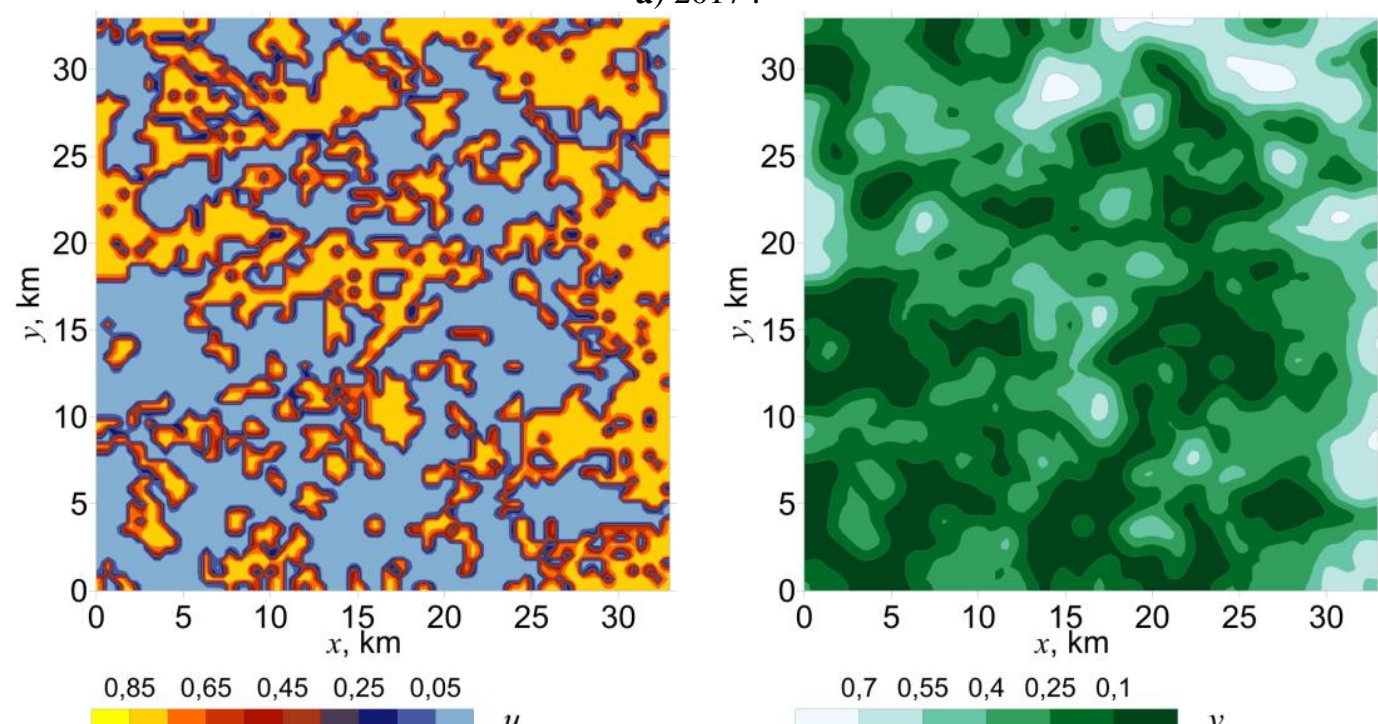

b) 2024 .
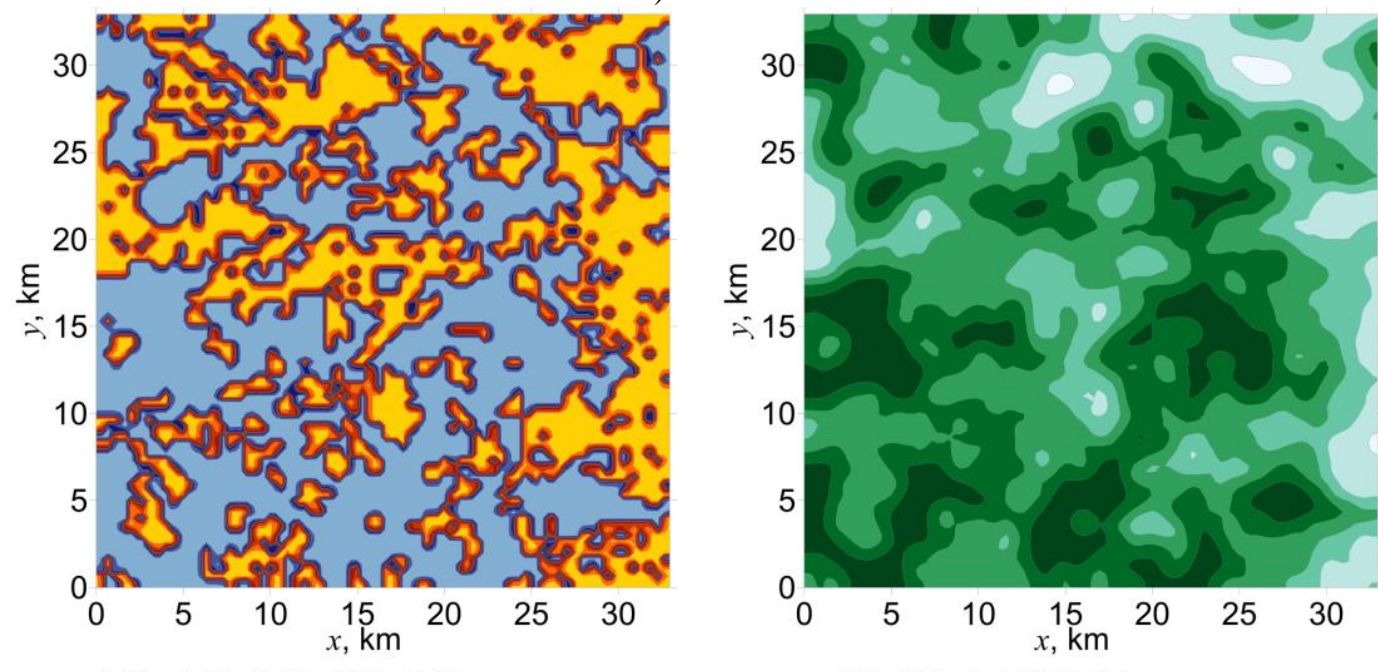

$\begin{array}{lllll}0,85 & 0,65 & 0,45 & 0,25 & 0,05\end{array}$

$\begin{array}{lllll}0,7 & 0,55 & 0,4 & 0,25 & 0,1\end{array}$

c) 2030 .

Fig. 7. New Moscow development model: a) 2017, the model initial conditions; b) the development up to 2024 year. c) the development up to 2030 year. $u$ is the square of the built-up area, $v$ is the square of destroyed geobiocenosis: $0.85-0.75$ - dense housing (multi-story buildings), $0.65-0.25-$ cottage development; $0.1-0.05$ - forests and park zone. 


\section{CONCLUSION}

Our approach is based on the ideas of autowave self-organization in active media. Analytical studies of the autowave system including the conditions for the existence of stationary or moving front solutions were published earlier by the authors and made it possible to create an adequate model for the development of urban ecosystems. Values of the model control parameters were obtained on the basis of aerial photography data and maps of the territories under investigation with use of authoring $\mathrm{C}++$ application, which forms text files from image-based data. The model developed is used to analyze and forecast the development of Moscow territory of until 2030.

The research was carried out within the framework of the Russian Science Foundation (project No. 18-11-00042).

\section{REFERENCES}

1. Forrester J.W. Urban Dynamics. MIT Press, Cambridge, Massachusetts. 290 p.

2. Makhov S.A. Mathematical modeling of world dynamics and sustainable development on the example of the Forrester's model: KIAM Preprint № 6. Moscow, 2005 (in Russ.).

3. Jianguo $\mathrm{Wu}$, John L. David. A spatially explicit hierarchical approach to modeling complex ecological systems: theory and applications. Ecological Modeling. 2002 V. 153. P. 7-26.

4. Changlin Y., Dingquan Y., Honghui Z., Shengjing Y., Guanghui C. Simulation of urban growth using a cellular automata-based model in a developing nation's region. International. Jornal jf Engeneering Sciens fnd Advancad Tecnology. 2012. V. 2. No. 3. P. 453-460.

5. Lizhong H., Lina T., Shenghui C., Kai Y. Simulating Urban Growth Using the SLEUTH Model in a Coastal Peri-Urban District in China. Sustainability. 2014. No. 6. P. 3899-3914.

6. Bihamta N., Soffianian A., Fakherran S., Gholamalifarm M. Using the SLEUTH Urban Growth Model to Simulate Future Urban Expansion of the Isfahan Metropolitan Area, Iran. Journal of the Indian Society of Remote Sensing. 2015. V. 43. P. 407-414. doi: 10.1007/s12524-014-0402-8

7. Alkheder S., Shan J. Cellular Automata Urban Growth Simulation and Evaluation - A Case Study of Indianapolis. In: Proceedings of the 8th International Conference on GeoComputation (University of Michigan, United States of America, 31 July - 3 August 2005). URL: http://www.geocomputation.org/2005/Alkheder (accessed 22.11.2018).

8. Vaz E., Arsanjani J.J. Predicting Urban Growth of the Greater Toronto Area - Coupling a Markov Cellular Automata with Document Meta-Analysis. Published. Journal of Environmental Informatics. 2015. V. 25. P. 71-80. doi: 10.3808/jei.201500299

9. Yeh A.G.-O., Li X. Urban Simulation Using Neural Networks and Cellular Automata for Land Use Planning. In: ISPRS Commission IV, Symposium 2002 Geospatial Theory: Processing and Applications (July 9-12, 2002, Ottawa, Canada). Eds. Costas Armenakis, Y.C. Lee. 2002. Article No. 36. URL: http://www.isprs.org/proceedings/XXXIV/part4/pdfpapers/036.pdf $\quad$ (accessed 22.11.2018).

10. Kolmogorov A.N., Petrovsky I.G., Piskunov N.S. Investigation of the diffusion equation connected with the increase of matter and its application to a single biological problem. Bull. Moscow State University, Section A. 1937. V. 1. No. 6. P. 1-26.

11. Zeldovich Ya.B., Frank-Kamenetsky D.A. On the theory of uniform flame propagation. Jour. Phys. Chemistry. 1938. V. 12. No. 1. P. 100-105. 
12. Yelkin Y.E. Autowave processes. Mathematical Biology and Bioinformatics. 2006. V. 1. No. 1. P. 27-40 (in Russ.). doi: 10.17537/2006.1.27

13. Hodgkin A., Huxley A. A quantitative description of membrane current and its application to conduction and excitation in nerve. J. Physiol. 1952. V. 117. P. 500-544.

14. Ataullakhanov F.I., Guria G.T. The spatial aspects of blood coagulation dynamics. Hypothesis. Biophysics. 1994. V. 39. No. 1. P. 89-95 (in Russ.).

15. Mann K.G. Is there value in kineticmodeling of thrombin generation? Yes. J. Thromb. Haemost. 2012. Vol. 10. No 8. P. 1463-1469. doi: 10.1111/j.1538-7836.2012.04799.x

16. Hemker H.C., Kerdelo S., Kremers R.M.W. Is there value in kinetic modeling of thrombin generation? J. Thromb. Haemost. 2012. V. 10. No. 8. P. 1470-1477.

17. FitzHugh R. Mathematical models of threshold phenomena in the nerve membrane. Bull. Math. Biophysics. 1955. No. 17. P. 257-278.

18. Nagumo J., Arimoto S., Yoshizawa S. An active pulse transmission line simulating nerve axon. Proc. IRE. 1962. V. 50. P. 2061-2070. doi: 10.1109/JRPROC.1962.288235

19. FitzHugh R., Impulses and Physiological States in Theoretical Models of Nerve Membrane. Biophysical Journal. 1961. V. 1. P. 445-466.

20. FitzHugh R. Mathematical models of excitation and propagation in nerve. In: Biological Engineering. Ed. Schwan H.P. N.-Y.: McGraw-Hill Book Co., 1969. P. 1-85.

21. Vasiliev V.A., Romanovsky Yu.M., Yakhno V.G. Autowave processes. M.: Nauka, 1987. 240 p. (in Russ.).

22. Sidorova A.E., Levashova N.T., Mel'nikova A.A., Yakovenko L.V. A model of a human dominated urban ecosystem as an active medium. Biophysics. 2015. V. 60. No. 3. P. 466-473.

23. Sidorova A.E., Mukhartova Yu.V., Yakovenko L.V. An Urban Ecosystem as a Superposition of Interrelated Active Media. Moscow University Physics Bulletin. 2014. V. 69. No. 5. P. 392-400.

24. Sidorova A.E., Levashova N.T., Mel'nikova A.A., Deryugina N.N., Semina A.E. Autowave Self-Organization in Heterogeneous Natural-Anthropogenic Ecosystems. Moscow University Physics Bulletin. 2016. V. 71. No. 6. P. 562-568.

25. Levashova N., Mel'nikova A., Semina A., Sidorova A. Autowave mechanisms of structure formation in urban ecosystems as the process of self-organization in active media. Communication on Applied Mathematics and Computation. 2017. V. 31. No. 1. P. 32-42.

26. Sidorova A.E., Levashova N.T., Mel'nikova A.A., Semina A.E. Model of the structure formation of urine ecosystems as a process of autowave self-organization in active media. Mathematical Biology and Bioinformatics. 2017. V. 12. No. 1. P. 186-197 (in Russ.). doi: $10.17537 / 2017.12 .186$

27. Levashova N.T., Mel'nikova A.A., Lukyanenko D.V., Sidorova A.E, Bytsyura S.V. Modeling of Urboecosystems as Self-Organization Processes. Math modeling. 2017. V. 29. 11. 11. P. 40-52 (in Russ.).

28. Savenko V.S. Geochemical aspects of sustainable development. Moscow: GEOS, 2003. 180 p. (in Russ.).

29. Levashova N.T., Mel'nikova A.A. Step-Like Contrast Structure in a Singularly Perturbed System of Parabolic Equations. Differential equations. 2015. V. 51. No. 3. P. 342-361.

30. Butuzov V.F., Levashova N.T., Mel'nikova A.A. A steplike contrast structure in a singularly perturbed system of elliptic equation. Computational mathematics and mathematical physics. 2013. V. 53. No. 9. P. 1239-1259.

31. Orlov A.O., Levashova N.T., Nefedov N.N. Solution of Contrast Structure Type for a Parabolic Reaction-Diffusion Problem in a Medium with Discontinuous Characteristics. Differential equations. 2018. V. 54. No. 5. P. 669-686. 
32. Levashova N.T., Nefedov N.N., Orlov A.O. Stationary reaction-diffusion equation with a discontinuous term. Computational Mathematics and Mathematical Physics. 2017. V. 57. No. 5. P. 854-866 (in Russ.).

33. Moscow Investment Portal. URL: https://investmoscow.ru/city-projects/aip/ (accessed 22.11.2018).

34. Complex urban policy and the construction of the city of Moscow. URL: https://stroi.mos.ru/infographics/novoi-moskvie-piat-liet-1/ (accessed 22.11.2018) (in Russ.)

35. Moscow Map. URL: https://yandex.ru/maps/213/moscow/ (accessed 22.11.2018) (in Russ.)

36. Map of the cottage settlement Marseille. URL: http://p-marsel.ru/map/ (accessed 22.11.2018) (in Russ.)

37. General Plan of Moscow. Western Valley the Suburb. URL: http://zapad.aprigorod.ru/genplan/ (accessed 22.11.2018) (in Russ.)

38. Norms and rules for designing the planning and development of Moscow (MGSN 1.0199). URL: http://docs.cntd.ru/document/1200003977 (accessed 22.11.2018) (in Russ.)

39. Kalitkin N.N., Koryakin P.V. Metody matematicheskoi fiziki (Methods of mathematical physics). M: "Academy", 2013. 304 p. (Numerical methods. Book 2) (in Russ.).

Received $\quad$ 02.10.2018, published 27.11.2018. 